\title{
Attachment Anxiety, Basic Psychological Needs Satisfaction and Depressive Symptoms in University Students: A Mediation Analysis Approach
}

\author{
Constantinos Kormas ${ }^{1}$, Georgia Karamali ${ }^{1} \&$ Fotios Anagnostopoulos ${ }^{1}$ \\ ${ }^{1}$ Department of Psychology, Panteion University of Social and Political Sciences, Athens, Greece \\ Correspondence: Constantinos Kormas, Department of Psychology, Panteion University of Social and Political \\ Sciences, 136 Syngrou Avenue, 17671, Athens, Greece. E-mail: konkormas@gmail.com
}

Received: March 8, 2014

Accepted: March 31, 2014 Online Published: May 20, 2014

doi:10.5539/ijps.v6n2p1

URL: http://dx.doi.org/10.5539/ijps.v6n2p1

\begin{abstract}
This study examined the mediating role of basic psychological needs satisfaction in the relationship between attachment anxiety and depressive symptoms in university students. The following measurement instruments were used to collect the data: Center for Epidemiologic Studies-Depression Scale, Experiences in Close Relationships Scale and Basic Psychological Needs Satisfaction General-Scale. Mediated effects were explored using a series of regression analyses and were further confirmed through bootstrapping procedures. Results revealed that basic psychological needs satisfaction partially mediated the relationship between attachment anxiety and depression. These results indicated that attachment anxiety was connected with depressive symptoms in more complicated ways than had traditionally been suggested. Implications of the findings targeting basic psychological needs satisfaction in anxiously attached university students with higher levels of depressive symptoms for clinical practice are discussed.
\end{abstract}

Keywords: attachment anxiety, basic psychological needs satisfaction, depressive symptoms, university students, mediation analysis

\section{Introduction}

University life is a particularly demanding period including highly challenging responsibilities, more complex academic tasks, new unfamiliar situations and a burst of ambitions for the future. For many students the university is the first experience of separation and living away from home, friends, romantic partners and familiar environment. In addition, university projects are more advanced and complicated than school tasks of past years. Furthermore, for the first time students undertake complex obligations and responsibilities without direct help of their families. In general, it seems that university life increases the demands in a very short time in various domains of students' lives. Taking into account all the above reasons, university life raises the possibilities for high levels of psychological distress. In this sense, depression is one of the most common psychological problems among university students (Buckanan, 2012; Dyson \& Renk, 2006). Thus, it is crucial to examine the factors which affect university students' ability to face these multilevel and different sources of stress in order to ensure the promotion of their optimal psychological functioning, well-being and academic success.

It has been suggested that long-term patterns of behavior and affect, which are formulated from the first years of life, significantly influence the process of adaption and coping with negative and stressful situations of adulthood life (Kendler et al., 2010). In this regard, attachment theory has become a broadly accepted framework for the study of the relations among primary experiences, personality patterns of behaviors and psychological distress (Meyer \& Pilkonis, 2005; Mikulincer \& Shaver, 2007). Attachment theory proposes mental representations models of self and others, attachment styles, patterns of affect regulation and a system of behaviors in a developmental perspective (Shorey \& Snyder, 2006). These styles of attachment and mental representations for self and others that are shaped in the beginning of life are transferred into adulthood and can affect the person's psychological functioning (Scharf, Mayseles, \& Kivenson-Baron, 2004; Waller, Scheidt, \& Hartmann, 2004).

In more detail, in the context of the attachment theory (Bowlby, 1969, 1973, 1980, 1988) it has been proposed that the quality of the relationship that the person develops with parents/caregivers in the early years of life 
significantly affects the psycho-socio-emotional development later. The responsiveness and availability of parents/caregivers lead to the formulation and development of internal working models of self and others (Pietromonaco \& Feldman Barrett, 2000). The inconsequent responsiveness, the emotional unavailability and the lack of reassurance from caregivers in early years of life can contribute to a negative working model of self in adulthood. These internal working models may determine the way in which a person experiences, expresses and processes emotions, thoughts and behaviors in all life-cycle environments and situations (Bretherton \& Munholland, 1999).

Hazan and Shaver (1987) suggested that the individuals' early experiences with their parents/caregivers can contribute to the development of either secure or insecure adult attachment. The secure or insecure attachment is associated with the individuals' ability to adequately address possible negative events in their lives, emotional problems and stressful situations (Kobak \& Sceery, 1988). Two types of adult insecure attachment have been proposed: anxious and avoidant (Brennan, Clark, \& Shaver, 1998; Mikulincer \& Shaver, 2007). Individuals with attachment anxiety have created a negative mental representation of an unworthy self, who does not deserve the love and care of others and is characterized by the fear of rejection, abandonment, as well as an excessive closeness and preoccupation with their partner (Lopez \& Brennan, 2000; Mallinckrodt, 2000). In contrast, individuals with attachment avoidance are characterized by an excessive fear of closeness, intimacy, and dependence and have a negative working model for others (Pietromonaco \& Feldman Barrett, 2000). Generally, relevant empirical studies have found that attachment anxiety shows a stronger positive connection with psychological distress than attachment avoidance (Mallinckrodt \& Wei, 2005; Wei, Heppner, \& Mallinckrodt, 2003).

In the relevant literature, it has been documented that insecure attachment shows a strong relationship with psychological distress, such as depressive symptoms in daily life. This strong link between adult attachment insecurity and depressive symptoms has been demonstrated by a plethora of modern empirical studies (Besser \& Priel, 2003; Davila et al., 2005; Hankin, Kassel, \& Abela, 2005; Shaver, Schachner, \& Mikulincer, 2005; Wei, Heppner, \& Mallinckrodt, 2003; Wei, Mallinckrodt, Russell, \& Abraham, 2004). In recent years, based on the hypothesis that insecure attachment can be distinguished from rigid dysfunctional behaviors and stable maladaptive psychological characteristics which hardly change (Fraley, 2002), research has been directed at identifying psychological factors that mediate the relationship between insecure attachment and psychological distress aiming to modify them and promote the psychological well-being (MacKinnon, Krull \& Lockwood, 2000). In this research area, it has been found that some of these mediator variables are social self-efficacy and emotional awareness (Mallinckrodt \& Wei, 2005), capacity for self-reinforcement and need for reassurance from others (Wei, Larson, Zakalik, \& Mallinckrodt, 2005), affect regulation (Wei, Vogel, Ku, \& Zakalik, 2005) and maladaptive perfectionism (Wei et al., 2004).

Towards this direction, it would be interesting to examine the concept of basic psychological needs satisfaction as it has been proposed by self-determination theory. Self-determination theory (Deci \& Ryan, 2000, 2002; Vansteenkiste, Niemiec, \& Soenens, 2010) is a macro-theory of human motivation, psychological growth, and mental wellness that emphasizes optimal functioning, psychological health and well-being, (Deci \& Ryan, 2008; Ryan \& Deci, 2008). Within the self-determination theory, the basic needs theory has been developed (Deci \& Ryan, 2000; Ryan \& Deci, 2000a; Van Petegem, Beyers, Vansteenkiste, \& Soenens, 2012). According to basic needs theory, three basic psychological needs for the development of psychological maturation, growth and optimal functioning are suggested. These include the psychological need for autonomy, competence and relatedness. The need for autonomy refers to an authentic sense of free volition, self-determination and selfdirection (Ryan \& Deci, 2000a). The need for competence refers to an experience of adequacy, sufficiency and creativity (Ryan \& Deci, 2000a). Finally, the need for relatedness refers to a sense of acceptance, closeness, intimacy and effective interaction with others (Ryan \& Deci, 2000a). In the relevant research literature, it has been demonstrated that satisfaction of these three basic psychological needs can contribute to positive functioning and psychological well-being in various life domains, such as work, education, and health (Baard, Deci, \& Ryan, 2004; Ferrer-Caja \& Weiss, 2000; Ng et al., 2012).

Furthermore, in the frame of self-determination, it has been proposed that satisfaction of psychological needs directly affects the intrinsic motivation, a psychological mechanism which nurtures the feeling of the external environment control (Ryan \& Deci, 2000a, 2002). The mechanism of intrinsic motivation or internalization contributes to development of the self-directed and autonomous behaviors that may promote the creation of a sense of a complete self which interacts effectively with the external environment and the others in various domains in daily life (Ryan \& Deci, 2002). The internalization of basic psychological needs for autonomy, competence and relatedness contributes to high levels of needs satisfaction (Niemiec \& Ryan, 2007; Ryan et al., 
2011; Ryan \& Deci, 2008). According to self-determination theory, the psychological growth is ensured when a person can accept, integrate and internalize ideas, values and behaviors which are initially motivated by external forces under the condition that psychological needs for autonomy, competence, and relatedness are satisfied in a needs-supportive motivational climate (Ryan \& Deci, 2000b, 2002, 2003).

A series of studies has shown that satisfaction of basic needs is strongly related to factors that can promote psychological health. It has been shown that satisfaction of the basic psychological needs has been positively associated with self-esteem (Thøgersen-Ntoumani \& Ntoumanis, 2007), life satisfaction (Meyer, Enstrom, Harstveit, Bowles, \& Beevers, 2007) and psychological functioning (Sheldon \& Niemiec, 2006). Furthermore, it has been documented that basic needs satisfaction is negatively related to psychological distress, such as depression (Wei et al., 2005) and anxiety (Deci et al., 2001). Moreover, empirical studies have shown a high correlation between adult attachment and basic psychological needs satisfaction. It has been found that individuals with secure attachment tend to experience high levels of basic psychological needs satisfaction (La Guardia, Ryan, Couchman, \& Deci, 2000). In contrast, Wei, Shaffer, Young, and Zakalik (2005) found that insecure adult attachment types showed a negative correlation with the satisfaction of basic psychological needs.

From the above review, it seems that insecure attachment can contribute to increased levels of psychological distress and is simultaneously related to lower levels of basic psychological needs satisfaction. In turn, the deficient satisfaction of basic psychological needs is associated with psychological dysfunctioning. Theoretically, these findings may indicate that insecure attachment can contribute to psychological distress (depression) not only via long-term maladaptive patterns of attachment orientation, but also through the insufficient basic psychological needs satisfaction. The purpose of this study was to examine the mediating role of basic psychological needs satisfaction between attachment anxiety and depressive symptoms in university students.

\section{Method}

\subsection{Participants and Procedure}

In total, 318 undergraduate students participated in the study. These university students were enrolled in the Department of Psychology at Panteion University of Social and Political Sciences, Athens and in the Department of Civil Engineering at the National Technical University of Athens. There were 216 women and 102 men, while age ranged from 18 to $25(\mathrm{M}=19.39, \mathrm{SD}=1.85)$. In terms of current relationship status, 129 participants reported that they were in a committed relationship and 189 identified themselves as single. Finally, all participants had Greek nationality. All undergraduate students could participate in the study without limitations. The questionnaires were administered to small groups of students and the participants were told that the study was related to thoughts and emotions about themselves and their close relationships. It took about 40 minutes to complete the given questionnaires. Respondents gave their informed consent to participate in the study. They were not placed at any significant mental or physical risk and could stop the procedure at any time. No personal identifying information was included in the questionnaires and participants were assured of the anonymity of their responses and the confidentiality of the data.

\subsection{Measures}

Attachment anxiety was measured with the Experiences in Close Relationships Scale (ECRS; Brennan et al., 1998). This scale is a 36-item self-report measure of adult attachment. Each item is answered on a 7-point Likert-type scale ranging from 1 (disagree strongly) to 7 (agree strongly). Participants rate how well each statement describes their typical feelings in close relationships. The results of a factor analysis identified two relatively orthogonal attachment dimensions: Anxiety and Avoidance. The Anxiety subscale (18 items) refers to fears of rejection and abandonment (e.g., "I worry about being abandoned"). The Avoidance subscale (18 items) measures fear of intimacy and discomfort with getting close to others or dependence (e.g., "I am nervous when partners get too close to me"). Higher scores on the Anxiety and Avoidance subscales indicate higher attachment anxiety and attachment avoidance, respectively. In the present study, the Greek version of the scale was used and was found to have satisfactory internal consistency reliability with Cronbach's alpha coefficient equal to .95 for the Anxiety subscale and .93 for the Avoidance subscale (Tsagarakis, Kafetsios, \& Stalikas, 2007).

Basic psychological needs satisfaction was assessed with the Basic Psychological Needs Satisfaction-General Scale (BPNG-S; Deci \& Ryan, 2001). The BPNS-General Scale contains 21 self-report items that measure basic psychological needs satisfaction. Each item is answered on a 7-point Likert-type scale ranging from 1 (disagree strongly) to 7 (agree strongly). Participants rate how well each psychological need is generally satisfied. The results of a factor analysis identified three relatively orthogonal psychological needs: autonomy (7 items, e.g., "I feel like I am free to decide for myself how to live my life"), competence (6 items, e.g., "Most days I feel a sense of accomplishment from what I do"), and relatedness ( 8 items, e.g., "I really like the people I interact with"). In 
the present study, this questionnaire was used for the first time with a Greek population under the kind permission of developers Edward Deci and Richard Ryan. The translation of this questionnaire into Greek was made only for this academic purpose and following standard forward and backward translation procedures. In this study, Cronbach's alpha coefficient was .90 for the autonomy subscale, .84 for competence subscale and .79 for the relatedness subscale. A total score was calculated reflecting basic psychological needs satisfaction.

Depressive symptoms were measured with Center for Epidemiologic Studies-Depression Scale (CES-D; Radloff, 1977). The CES-D is a 20-item scale measuring current levels of depressive symptoms (e.g., "I had trouble keeping my mind on what I was doing."). Participants could answer items on a 4-point Likert scale ranging from 0 (rarely or none of the time [less than 1 day]) to 3 (most or all of the time [5-7 days]), based on the frequency with which the items reflected participants' experiences during the past week. Scores range from 0 to 60 , with higher scores indicating higher levels of depressive mood and symptoms. The Greek version of CES-D has shown satisfactory internal consistency reliability, with Cronbach's alpha coefficient equal to .76. (Fountoulakis et al., 2001).

\subsection{Statistical Analysis}

All data analyses were conducted using SPSS (version 15.0). Path analytic techniques were utilized to test for mediated effects. According to Baron and Kenny (1986), mediation is established when the following three conditions are met: (1) the independent variable is a significant predictor of the dependent variable, (2) the independent variable is a significant predictor of the mediator, (3) the mediator is a significant predictor of the dependent variable. Finally, if the effect of the independent variable on the dependent variable controlling for mediator is zero then, a full mediation is established, or alternatively, if it is still significant, then there is a partial mediation. To address the robustness of the estimated confidence intervals and the standard errors of the mediated effects, a bootstrap analysis was conducted using an SPSS macro (Shrout \& Bolger, 2002). The bootstrapping is realized by extracting a large number of samples from the data, applying sampling with replacement as to the original sample size and computing the indirect effect in each sample (Preacher \& Hayes, 2004). Current data were analysed by setting the bootstrap to 5000 replications and constructing $95 \%$ CIs around the mediated effects.

\section{Results}

\subsection{Descriptive Statistics}

Means, standard deviations and correlations for the three measured variables are shown in the following Table 1.

Table 1. Means, standard deviations and correlations among the 3 main variables

\begin{tabular}{|c|c|c|c|c|c|c|}
\hline Variables & $\mathrm{M}$ & SD & 1 & 2 & & 3 \\
\hline $\begin{array}{l}\text { Attachment } \\
\text { Anxiety }\end{array}$ & 25.51 & 6.58 & - & & $-.241^{*}$ & $184^{*}$ \\
\hline $\begin{array}{l}\text { Basic } \\
\text { Psychological } \\
\text { Needs } \\
\text { Satisfaction }\end{array}$ & 73.04 & 21.64 & & - & & $-.138 *$ \\
\hline $\begin{array}{l}\text { Depressive } \\
\text { Symptoms }\end{array}$ & 16.69 & 8.78 & & & & - \\
\hline
\end{tabular}

\subsection{Mediating Effect of Basic Psychological Needs Satisfaction}

Multiple regression analyses were applied to assess each component of the proposed mediation model. In the first step, it was found that attachment anxiety was positively associated with depressive symptoms $(\mathrm{B}=.067, t$ $=3.34, p<.05)$. In the second step, it was found that attachment anxiety was negatively related to basic psychological needs satisfaction $(\mathrm{B}=-.218, t=4.421, p<.05)$. Lastly, in the third step results indicated that the basic psychological needs satisfaction was negatively associated with depressive symptoms $(\mathrm{B}=-.077, t=$ $-3.468, p<.05$ ). Because all the above paths were statistically significant, the hypothesized mediation model could be confirmed and further mediation was tested using the bootstrapping method with bias-corrected 
confidence estimates (MacKinnon, Lockwood, \& Williams, 2004; Preacher \& Hayes, 2004). In the present study, the $95 \%$ confidence interval of the indirect effects was obtained with 5000 bootstrap resamples (Preacher \& Hayes, 2008). Results of the mediation analysis confirmed the mediating role of basic psychological needs satisfaction in the relation between attachment anxiety and the experiencing of depressive symptoms $(\mathrm{B}=.017$; $\mathrm{CI}=.007$ to .33$)$. In addition, results indicated that the direct effect of attachment anxiety on the experiencing of depressive symptoms remained significant $(\mathrm{B}=.084, t=4.129, p<.05)$ when controlling for basic psychological needs satisfaction, thus suggesting partial mediation. Finally, to control for the effects of sex and commitment to a current relationship, we also estimated the partial effects of these two variables on depressive symptoms. However, there were no significant relationships with depression (at $5 \%$ level of significance).

Table 2. Partitioning of paths from attachment anxiety (AA) to depressive symptoms (DS) through basic psychological needs satisfaction (BPNS)

\begin{tabular}{lllll}
\hline Effect & $\mathrm{B}$ & $S E$ & $t$ & $p$ \\
\hline $\mathrm{AA} \rightarrow \mathrm{DS}$ & .067 & .020 & 3.335 & $<.05$ \\
$\mathrm{AA} \rightarrow \mathrm{BPNS}$ & -.218 & .049 & -4.421 & $<.05$ \\
$\mathrm{BPNS} \rightarrow$ DS & -.077 & .022 & -3.468 & $<.05$ \\
$\mathrm{AA} \rightarrow$ BPNS $\rightarrow$ DS & .0169 & .020 & 4.129 & $<.05$ \\
\hline
\end{tabular}

\section{Discussion}

The results of this study provide a more extended and expendable understanding of the connection between attachment anxiety and depressive symptoms in university students. An important finding was that the degree of satisfaction of basic psychological needs mediated the relationship between attachment anxiety and depressive symptoms. The above finding indicates that the total association between attachment anxiety and depression is not only direct, but also that attachment anxiety contributes to increased levels of depression through the reduced levels of satisfaction of basic psychological needs. As a result, university students with higher levels of attachment anxiety tended to experience satisfaction of basic psychological needs at lower levels, which in turn contributed to the emergence of depressive symptoms in their daily life.

The findings of the present study appear to be consistent with the attachment theory assumption that persons with higher levels of attachment anxiety have structured a negative representation model of an unworthy self. Further, it has been found that persons with attachment anxiety show limited ability for internal reassurance and self locus of control (Wei et al., 2005). Traditionally, it has been suggested that some possible psychological causalities of depressive symptoms are the inability for self-reinforcement (Davila, 2001), the lack of internal reassurance (Bandura, 1971; Lewinsohn, 1974), and the structure of a negative self model (Beck, 1967). Therefore, the negative model of self in combination with the inability for internal validity and reassurance may lead to dysfunction of the psychological mechanism of intrinsic motivation that, according to the selfdetermination theory, is crucial for the satisfaction of basic psychological needs (Ryan et al., 2011; Ryan \& Deci, 2008. Thus, the quality of insecure attachment orientation via maladaptive psychological mechanisms undermines the processes of basic needs fulfillment. Consequently, university students with higher levels of attachment anxiety who have a negative model of themselves were more susceptible to experiencing a deficient satisfaction of basic psychological needs, which increased their vulnerability for depressive symptoms. Taking into account that psychological mediators can be modified or modulated in psychotherapeutic sessions (MacKinnon, Krull, \& Lockwood, 2000), therapeutic interventions focused on basic psychological needs satisfaction need to be planned in order to help university students with anxiety attachment to cope and progressively reduce their levels of distress.

It seems that some difficulties which result from depressive symptoms with which university students suffer have origins in attachment anxiety orientation that do not allow them sufficiently to satisfy their basic psychological needs for autonomy, competence and relatedness. In this direction, college counselors need to help students understand the connection between attachment anxiety and deficient satisfaction of basic needs and show them how the defective satisfaction of basic needs can contribute to their current problems of depressive symptoms. In addition, college counselors must assist students to understand how basic needs work and interact in various domains of life, under what conditions they are promoted or undermined and how to develop effective strategies to satisfy basic needs in their daily life. It is crucial for the effectiveness of therapeutic process that 
students accept, adopt and internalize the new behaviors which are related to basic needs satisfaction in a needs-supportive therapeutic climate. The behaviors-target has to result from a non-controlling discussion and the active participation of the student, so that promotion of instinct motivation is enabled.

Intervention programs have to help participants to meet, identify and satisfy the psychological needs of autonomy, competence, and relatedness only in a frame of a needs-supportive motivational climate. A needs-supportive motivational climate is ensured when individuals have the space to choose, activate and work independently, take initiative, show their capabilities, freely express their thoughts and feelings without criticism and controlling feedback (Gagné et al., 2003; Moreau \& Mageau, 2012). The existence of a motivational climate could more effectively support the mechanisms of internalization which in turn can promote the satisfaction of the three basic psychological needs. In turn, higher levels of psychological needs internalization and satisfaction would lead to greater levels of psychological functioning (Niemiec \& Ryan, 2007) and decreased levels of depressive mood.

Moreover, students with attachment anxiety may benefit from psycho-education interventions targeted to the development of their skills, which are related to basic psychological needs fulfillment (Hodge, Danish, \& Martin, 2012). College counselors need to design interventions to improve these skills, which would help students meet their basic needs, and in turn, lead to decreased levels of depressive symptoms. Interventions aimed at increasing levels of autonomy could be focused on skills that promote self-regulation, internal locus of control, self-control and independent, creative and critical thinking. Also, satisfaction of the psychological need for competence could be improved by applying psychoeducational programs based on teaching problem-solving and coping skills. Furthermore, social support, training in social skills, communication and conservation competences, empathy skills, increased cooperation with others and enhanced social interest should be included in order to strengthen the psychological need for relatedness. Finally, it is critical for the above mentioned interventions to establish a sense of satisfaction's balance both among the three basic psychological needs (Sheldon \& Niemic, 2006) and the different life's domains (Milyavska et al., 2009), so that psychological well-being is more naturally and effectively promoted.

Some limitations of this study should be acknowledged. The sample was restricted to Greek university students who accepted to participate in the study. So research finding may not be generalizable to other ethnic population students. In addition, only the style of attachment anxiety was examined in the present study. Future studies need to include the avoidant attachment type. Moreover, attachment anxiety, satisfaction of basic psychological needs and depressive symptoms were measured using self-report instruments, and, therefore, participants' responses might have been affected by social desirability and bias. Finally, instead of using a more advanced and sophisticated statistical model of mediation analysis, the results of the present study do not provide evidence for causal relationships, but only possible correlational associations between variables.

Future research needs to use multiple measures of attachment anxiety, satisfaction of basic psychological needs and depressive symptoms, with data based on interviews or multiple sources of information, such as partners, friends or family members. Also, it would be useful to make similar investigations in different student populations, such as students from ethnically diverse cultures. Finally, the effectiveness of the intervention focused on improving basic psychological needs aiming at reducing university students' distress would need to be evaluated in future research.

In conclusion, it can be suggested that the concept of basic psychological needs constitutes a useful clinical tool which can be utilized in processes of case formulation, intervention design and applying of treatment on students with psychological distress and maladaptive attachments patterns of behavior (Lynch \& Levers, 2007). Finally, we could conclude that this kind of studies has a crucial role in deeply understanding of the complex nature of the relation between insecure attachment and distress, because they help us understand how different insecure attachment patterns may lead to or increase the vulnerability to specific types of distress through maladaptive psychological mediating mechanisms. Knowledge from this area of empirical studies needs to be applied in daily clinical practice via appropriate interventions which must take into account the finding that insecure attachment patterns and particular mediators are connected with specific types of maladaptive psychological functioning.

\section{References}

Baard, P. P., Deci, E. L., \& Ryan, R. M. (2004). Intrinsic need satisfaction: A motivational basis of performance and well-being in two work settings. Journal of Applied Social Psychology, 34, 2045-2068. http://dx.doi.org/10.1111/j.1559-1816.2004.tb02690.x

Bandura, A. (1971). Vicarious and self-reinforcement processes. In R. Glaser (Ed.), The nature of reinforcement. New York: Academic Press. 
Baron, M. R., \& Kenny, D. A. (1986). The moderator-mediator variable distinction in social psychological research: Conceptual, strategic, and statistical considerations. Journal of Personality and Social Psychology, 51, 1173-1182. http://dx.doi.org/10.1037/0022-3514.51.6.1173

Beck, A. T. (1967). Depression: Clinical, experimental, and theoretical aspects. New York: Harper \& Row.

Besser, A., \& Priel, B. (2003). A multisource approach to self-critical vulnerability to depression: The moderating role of attachment. Journal of Personality, 71, 515-555. http://dx.doi.org/10.1111/1467-6494.7104002

Bowlby, J. (1969). Attachment and loss. New York: Basic Books.

Bowlby, J. (1973). Attachment and loss: Vol. 2. Separation: Anxiety and anger. New York: Basic Books.

Bowlby, J. (1980). Attachment and loss: Vol. 3. Sadness and depression. New York: Basic Books.

Bowlby, J. (1988). A secure base: Parent-child attachment and healthy human development. New York: Basic Books.

Brennan, K. A., Clark, C. L., \& Shaver, P. R. (1998). Self-report measurement of adult attachment: An integrative overview. In J. A. Simpson, \& W. S. Rholes (Eds.), Attachment theory and close relationships (pp. 46-76). New York: Guilford Press.

Bretherton, I., \& Munholland, A. (1999). Internal Working Models in Attachment Relationships: A Construct Revisited. In J. Cassidy, \& P. R. Shaver (Eds.), Handbook of Attachment: Theory, Research and Clinical Applications (pp. 89-114). New York: Guilford Press

Buchanan, J. L. (2012). Prevention of Depression in the College Student Population: A Review of the Literature. Archives of Psychiatric Nursing, 26, 21-42. http://dx.doi.org/10.1016/j.apnu.2011.03.003

Davila, J. (2001). Refining the association between excessive reassurance seeking and depressive symptoms: The role of related interpersonal constructs. Journal of Social and Clinical Psychology, 20, 538-559. http://dx.doi.org/10.1521/jscp.20.4.538.22394

Davila, J., Ramsay, M., Stroud, C. B., \& Steinberg, S. (2005). Attachment as vulnerability to the development of psychopathology. In B. L. Hankin, \& J. R. Z. Abela (Eds.), Development of psychopathology: A vulnerability-stress perspective (pp. 215-242). Thousand Oaks, CA: Sage. http://dx.doi.org/10.4135/9781452231655.n9

Deci, E. L., \& Ryan, R. M. (2000). The "what" and "why" of goal pursuits: Human needs and the

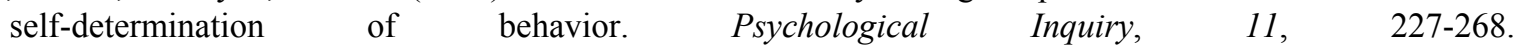
http://dx.doi.org/10.1207/S15327965PLI1104_01

Deci, E. L., Ryan, R. M., Gagnı, M., Leone, D. R., Usunov, J., \& Kornazheva, B. P. (2001). Need satisfaction, motivation, and well-being in the work organizations of a former eastern bloc country: A cross-cultural study of self-determination. Personality and Psychology Bulletin, 27, 930-942. http://dx.doi.org/10.1177/0146167201278002

Deci, E. L., \& Ryan, R. M. (2002). Handbook of self-determination research. Rochester, NY: University of Rochester Press.

Deci, E., \& Ryan, R. (2008). Facilitating optimal motivation and psychological wellbeing across life's domains. Canadian Psychology, 49, 14-23. http://dx.doi.org/10.1037/0708-5591.49.1.14

Dyson, R., \& Renk, K. (2006). Freshmen Adaptation to University Life: Depressive Symptoms, Stress, and Coping. Journal of Clinical Psychology, 62, 1231-1244. http://dx.doi.org/10.1002/jclp.20295

Ferrer-Caja, E., \& Weiss, M. R. (2000). Predictors of intrinsic motivation among adolescent students in physical education. Research Quarterly for Exercise \& Sport, 71, 267-279. http://dx.doi.org/10.1080/02701367.2000.10608907

Fountoulakis, K., Iacovides, A., Kleanthous, S., Samolis, S., Kaprinis, S., Sitzoglou, K., ... Bech, P. (2001). Reliability, Validity and Psychometric Properties of the Greek Translation of the Center for Epidemiological Studies-Depression (CES-D) Scale. BMC Psychiatry, 1(3), 47-55.

Fraley, C. R. (2002). Attachment Stability from Infancy to Adulthood: Meta-Analysis and Dynamic Modeling of Developmental Mechanisms. Personality and Social Psychology Review, 6, 123-151. http://dx.doi.org/10.1207/S15327957PSPR0602_03 
Gagné, M. (2003). The role of autonomy support and autonomy orientation in prosocial behavior engagement. Motivation \& Emotion, 27, 199-223. http://dx.doi.org/10.1023/A:1025007614869

Hankin, B. L., Kassel, J. D., \& Abela, J. R. Z. (2005). Adult attachment dimensions and specificity of emotional distress symptoms: Prospective investigations of cognitive risk and interpersonal stress generation as mediating mechanisms. Personality Social Psychology Bulletin, 3, 136-151. http://dx.doi.org/10.1177/0146167204271324

Hazan, C., \& Shaver P. R. (1987). Romantic love conceptualized as an attachment process. Journal of Personality and Social Psychology, 52, 511-524. http://dx.doi.org/10.1037/0022-3514.52.3.511

Hodge, K., Danish, S., \& Martin, J. (2012). Developing a Conceptual Framework for Life Skills Interventions. The Counseling Psychologist, 41, 1125-1152. http://dx.doi.org/10.1177/0011000012462073

Kendler, K. S., Aggen, S. H., Knudsen, G. P., Roysamb, E., Neale, M. C., \& Reichborn-Kjennerud, T. (2010). The structure of genetic and environmental risk factors for syndromal and subsyndromal common DSM-IV axisI and axisII disorders. American Journal of Psychiatry, 168, 29-39. http://dx.doi.org/10.1176/appi.ajp.2010.10030340

Kobak, R. R., \& Sceery, A. (1988). Attachment in late adolescence: Working models, affect regulation, and representations of self and others. Child Development, 59, 135-146. http://dx.doi.org/10.2307/1130395

La Guardia, J. G., Ryan, R. M., Couchman, C. E., \& Deci, E. L. (2000). Within-person variation in security of attachment: A self-determination theory perspective on attachment, need fulfillment, and well-being. Journal of Personality \& Social Psychology, 79, 367-384. http://dx.doi.org/10.1037/0022-3514.79.3.367

Lewinsohn, P. M. (1974). A behavioral approach in depression. In R. J. Friedman, \& M. M. Katz (Eds.), The psychology of depression: Contemporary theory and research (pp. 157-185). Washington, DC: Winston.

Lopez, F. G., \& Brennan, K. A. (2000). Dynamic processes underlying adult attachment organization: Toward an attachment theoretical perspective on the healthy and effective self. Journal of Counseling Psychology, 47, 283-301. http://dx.doi.org/10.1037/0022-0167.47.3.283

Lynch, M. F., \& Levers, L. L. (2007). Ecological-transactional and motivational perspectives in counseling. In J. Gregoire, \& C. Jungers (Eds.), The counselor's companion: What every beginning counselor needs to know (pp. 586-605). Mahwah, NJ: Lawrence Erlbaum Associates.

MacKinnon, D. P., Krull, J. L., \& Lockwood, C. (2000). Mediation, confounding, and suppression: Different names for the same effect. Prevention Science, 1, 173-181. http://dx.doi.org/10.1023/A:1026595011371

MacKinnon, D. P., Lockwood, C. M., \& Williams, J. (2004). Confidence limits for the indirect effect: Distribution of the product and resampling methods. Multivariate Behavioral Research, 39, 99-128. http://dx.doi.org/10.1207/s15327906mbr3901_4

Mallinckrodt, B. (2000). Attachment, social competencies, and interpersonal process in psychotherapy. Psychotherapy Research, 10, 239-266. http://dx.doi.org/10.1093/ptr/10.3.239

Mallinckrodt, B., \& Wei, M. (2005). Attachment, social competencies, social support, and psychological distress. Journal of Counseling Psychology, 52, 358-367. http://dx.doi.org/10.1037/0022-0167.52.3.358

Meyer, B., \& Pilkonis, P. A. (2005). An attachment model of personality disorders. In M. F. Lenzenweger, \& J. F. Clarkin (Eds.), Major Theories of Personality Disorder (pp. 231-281). New York: GuilfordPress.

Meyer, B., Enstrom, M. K., Harstveit, M., Bowles, D. P., \& Beevers, C. G. (2007). Happiness and despair on the catwalk: Need satisfaction, well-being, and personality adjustment among fashion models. The Journal of Positive Psychology, 2, 2-17. http://dx.doi.org/10.1080/17439760601076635

Moreau, E., \& Mageau, G. (2012). The importance of perceived autonomy support for the psychological health and work satisfaction of health professionals: Not only supervisors count, colleagues too! Motivation \& Emotion, 36, 268-286. http://dx.doi.org/10.1007/s11031-011-9250-9

Mikulincer, M., \& Shaver, P. (2007). Attachment in Adulthood: Structure, Dynamics, and Change. New York: Guilford Press.

Milyavska, M., Gingras, I., Mageau, M., Koestner, R., Gagnon, H., Fang, J., \& Boiche, J. (2009). Balance across contexts: Importance of balanced needs satisfaction across various life domains. Personality \& Social Psychology Bulletin, 35, 1031-1045. http://dx.doi.org/10.1177/0146167209337036 
Ng, J. Y. Y., Ntoumanis, N., Thøgersen-Ntoumani, C., Deci, E. L., Ryan, R. M., Duda, J. L., \& Williams, G. C. (2012). Self-Determination Theory Applied to Health Contexts: A Meta-Analysis. Perspectives on Psychological Science, 7, 325-340. http://dx.doi.org/10.1177/1745691612447309

Niemiec, C., \& Ryan, R. (2007). Autonomy, competence, and relatedness in the classroom: Applying self-determination theory to educational practice. Theory \& Research in Education, 7, 133-144. http://dx.doi.org/10.1177/1477878509104318

Pietromonaco, P. R., \& Feldman, B. L. (2000). The internal working models concept: What do we really know about the self in relation to others? Review of General Psychology, 4, 155-175. http://dx.doi.org/10.1037/1089-2680.4.2.155

Preacher, K. J., \& Hayes, A. F. (2004). SPSS and SAS procedures for estimating indirect effects in simple mediation models. Behavior Research Methods, Instruments, and Computers, 36, 717-731. http://dx.doi.org/10.3758/BF03206553

Preacher, K. J., \& Hayes, A. F. (2008). Asymptotic and resampling strategies for assessing and comparing indirect effects in multiple mediator models. Behavior Research Methods, 40, 879-891. http://dx.doi.org/10.3758/BRM.40.3.879

Radloff, L. S. (1977). The CES-D scale: A self-report depression scale for research in the general population. Applied Psychological Measurement, 1, 385-401. http://dx.doi.org/10.1177/014662167700100306

Ryan, R. M., \& Deci, E. L. (2000a). The darker and brighter sides of human existence: Basic psychological needs as a unifying concept. Psychological Inquiry, 11, 319-338. http://dx.doi.org/10.1207/S15327965PLI1104_03

Ryan, R. M., \& Deci, E. L. (2000b). Self-determination theory and the facilitation of intrinsic motivation, social $\begin{array}{lllll}\text { development, and } \quad \text { well-being. American } & \text { Psychologist, }\end{array}$ http://dx.doi.org/10.1037/0003-066X.55.1.68

Ryan, R. M., \& Deci, E. L. (2003). On assimilating identities to the self: A self determination theory perspective on internalization and integrity within cultures. In M. R. Leary, \& J. P. Tangney (Eds.), Handbook of self and identity (pp. 253-272). New York, NY: Guilford Press.

Ryan, R. M., \& Deci, E. L. (2008). A self-determination theory approach to psychotherapy: The motivational basis for effective change. Canadian Psychology, 49, 186-193. http://dx.doi.org/10.1037/a0012753

Ryan, R. M., Lynch, M. F., Vansteenkiste, M., \& Deci, E. L. (2011). Motivation and autonomy in counseling, psychotherapy, and behavior change: A look at theory and practice. The Counseling Psychologist, 39, 193-260. http://dx.doi.org/10.1177/0011000009359313

Scharf, M., Mayseles, O., \& Kivenson-Baron, I. (2004). Adolescents' attachment representations and developmental tasks in emerging adulthood. Developmental Psychology, 40, 430-444. http://dx.doi.org/10.1037/0012-1649.40.3.430

Shaver, P. R., Schachner, D. A., \& Mikulincer, M. (2005). Attachment style, excessive reassurance seeking, relationship processes, and depression. Personality and Social Psychology Bulletin, 31, 343-359. http://dx.doi.org/10.1177/0146167204271709

Sheldon, K. M., \& Niemiec, C. P. (2006). It's not just the amount that counts: Balanced need satisfaction also affects well-being. Journal of Personality and Social Psychology, 91, 331-341. http://dx.doi.org/10.1037/0022-3514.91.2.331

Shorey, H. S., \& Snyder, C. R. (2006). The role of adult attachment styles in psychopathology and psychotherapy outcomes. Review of General Psychology, 10, 1-20. http://dx.doi.org/10.1037/1089-2680.10.1.1

Shrout, P. E., \& Bolger, N. (2002). Mediation in experimental and non experimental studies: New procedures and recommendations. Psychological Methods, 7, 422-445. http://dx.doi.org/10.1037/1082-989X.7.4.422

Thøgersen-Ntoumani, C., \& Ntoumanis, N. (2007). A self-determination theory approach to the study of body image concerns, self-presentation and self-perceptions in a sample of aerobic instructors. Journal of Health Psychology, 12, 301-315. http://dx.doi.org/10.1177/1359105307074267

Tsagarakis, M., Kafetsios, K., \& Stalikas, A. (2007). Reliability and Validity of the Greek Version of the Revised Experiences in Close Relationships Measure of Adult Attachment. European Journal of Psychological Assessment, 23, 47-55. http://dx.doi.org/10.1027/1015-5759.23.1.47 
Vansteenkiste, M., Niemiec, C. P., \& Soenens, B. (2010). The development of the five mini-theories of self-determination theory: A historical overview, emerging trends and future directions. In T. Urdan, \& S. Karabenick (Eds.), Advances in motivation and achievement (pp. 105-166). Bingley, UK: Emerald.

Van Petegem, S., Beyers, W., Vansteenkiste, M., \& Soenens, B. (2012). On the association between adolescent autonomy and psychosocial functioning: Examining decisional independence from a Self-Determination Theory perspective. Developmental Psychology, 48, 76-88. http://dx.doi.org/10.1037/a0025307

Waller, E., Scheidt, C. E., \& Hartmann, A. (2004). Attachment representation and illness behaviour in somatoform disorders. Journal of Nervous and Mental Disease, 192, 200-209. http://dx.doi.org/10.1097/01.nmd.0000116463.17588.07

Wei, M., Heppner, P. P., \& Mallinckrodt, B. (2003). Perceived coping as a mediator between attachment and psychological distress: A structural equation modeling approach. Journal of Counseling Psychology, 50, 438-447. http://dx.doi.org/10.1037/0022-0167.50.4.438

Wei, M., Mallinckrodt, B., Russell, D. W., \& Abraham, T. W. (2004). Maladaptive perfectionism as a mediator and moderator between adult attachment and depressive mood. Journal of Counseling Psychology, 51, 201-212. http://dx.doi.org/10.1037/0022-0167.51.2.201

Wei, M., Larson, L. M., Zakalik, R. A., \& Mallinckrodt, B. (2005). Adult Attachment, Depressive Symptoms, and Validation From Self Versus Others. Journal of Counseling Psychology, 52, 368-377. http://dx.doi.org/10.1037/0022-0167.52.3.368

Wei, M., Vogel, D. L., Ku, T.-Y., \& Zakalik, R. A. (2005). Adult attachment, affect regulation, negative mood, and interpersonal problems: The mediating roles of emotional reactivity and emotional cutoff. Journal of Counseling Psychology, 52, 14-24. http://dx.doi.org/10.1037/0022-0167.52.1.14

Wei, M., Shaffer, P. A., Young, S. K., \& Zakalik, R. A. (2005). Adult Attachment, Shame, Depression, and Loneliness: The Mediation Role of Basic Psychological Needs Satisfaction. Journal of Counseling Psychology, 52, 591-601. http://dx.doi.org/10.1037/0022-0167.52.4.591

\section{Copyrights}

Copyright for this article is retained by the author(s), with first publication rights granted to the journal.

This is an open-access article distributed under the terms and conditions of the Creative Commons Attribution license (http://creativecommons.org/licenses/by/3.0/). 